\title{
Are Relational Contracting Approaches Applicable to Public Projects in China?
}

\begin{abstract}
Rising complexities in construction projects management has boosted the importance of relational contracting $(\mathrm{RC})$ in the field. $\mathrm{RC}$ is based on recognition of mutual benefits and win-win scenarios gained through more cooperative relationships between contracting parties. There have been a range of RC initiatives across many countries towards deeper collaborative relationships; however, such formal RC approaches are not yet well established in China. In this paper, the feasibility of implementing $\mathrm{RC}$ in the China's public construction projects is investigated. The results indicate that $\mathrm{RC}$ is highly feasible for implementation in China due to its theoretical benefits, its alignment to Chinese culture, and its behaviors in past public construction projects. Three strategies for facilitating the implementation of $\mathrm{RC}$ in China are proposed.
\end{abstract}

Keywords: relational contracting, public construction, relationship

\section{Introduction}

An appropriate contracting method coupled with clear and

Manuscript received June 16, 2014; accepted September 30, 2014

Wei-ya Hao

School of Economics and Management, Beijing Jiaotong University, Beijing 100044, China

Beijing Infrastructure Investment Co., Ltd., Beijing 100101, China

Hui-ping Ding

School of Economics and Management, Beijing Jiaotong University, Beijing 100044, China

Yong-jian $\mathrm{Ke}(\bowtie)$

School of Architecture and Built Environment, The University of Newcastle, Callaghan NSW 2308, Australia

Email: yongjian.ke@newcastle.edu.au

Ying-ying Wang

Beijing Infrastructure Investment Co., Ltd., Beijing 100101, China equitable contract documents does not ensure project success because the attitudes of the contracting parties and the relationships among the contracting parties are equally important (Rahman \& Kumaraswamy, 2002). Contracting parties usually tend to act in an atomized manner and look out for their own personal interests. Barriers also arise from the highly fragmented nature in a construction project especially between design and construction. Rahman and Kumaraswamy (2002) found that collaborative transaction through the adoption of relational contracting (RC) practices may be useful in reducing transaction costs as well as fostering co-operative relationships and better teamwork. The use of collaborative transactions may also reduce disputes and increase team harmony, thereby leading to better project performance (Walker, 1998).

The term "RC" in this paper refers to the definition by Yeung et al. (2012) that it is a set of principles and philosophy of contracting based on relationships, with five core elements including "commitment", "trust", "cooperation and communication", "common goals and objective", and "win-win philosophy". In other words, RC is based on recognition of mutual benefits and win-win scenarios through more cooperative relationships between contracting parties (Rahman \& Kumaraswamy, 2004). It underpins a range of approaches such as partnering, alliance, joint venture and other collaborative working arrangements.

To the best of the authors' knowledge, there is no such formal RC approach in place in China yet. The most relevant approach in place is the public private partnership (PPP), which is promoted by the Chinese government in order to reduce the fiscal stress. This approach however has weakness since it does not improve the efficiency. Furthermore, PPP is a long-term relationship-based contract which usually integrates the design process with build and operation, whereas RC is more likely to be a short-term relationship-based contract integrating the key contracting parties as a team. Basing on that motivation therefore, the main aim of this study is to investigate the feasibility of implementation of RC approaches in the China's public construction projects. 


\section{International implementations of RC approaches}

A range of RC approaches have been implemented across many countries to facilitate deeper collaborative relationships. Among them, three main RC approaches can behave been adopted globally in the practice (Lahdenperä, 2012), namely project partnering (PP), alliance contracting (AC) and integrated project delivery (IPD).

\subsection{Project partnering (PP)}

PP has the longest traceable history of RC contractual arrangements (Lahdenperä, 2012). It is defined as a longterm commitment between two or more organizations for the purpose of achieving specific business objectives by maximizing the effectiveness of each participant's resources (Construction Industry Institute, 1991). It is based upon trust, dedication to common goals, and an understanding of each other's individual expectations and values. PP has been widely used in the construction industry; nevertheless, most of the implementations have been non-contractual. PPC2000 developed by the Association of Consultant Architects in UK is the first standard form PP contract, where the partnering principles are taken into the agreement itself and are not only optional or in an additional agreement (Association of Consultant Architects, 2008). In Hong Kong, the Development Bureau is keen to gain experience using the third edition of New Engineering Contract on public works which is considered a contractual PP arrangement as well due to some past unsuccessful partnering experiences.

\subsection{Alliance contracting (AC)}

Extensive criticisms of the construction industry in the 1990s in Australia led to initiatives and general consensus that an integrated and seamless supply chain is required in the construction industry (Cox \& Ireland, 2002). As a formal contracting arrangement, $\mathrm{AC}$ is an innovative and integrated procurement method for infrastructure projects and has been commonly accepted in the public infrastructure sector (Davis \& Love, 2011). AC now represents one third of the total value of public infrastructure sector projects delivered in Australia (Department of Infrastructure and Transport, 2011).

\subsection{Integrated project delivery (IPD)}

IPD is a relatively recent addition to the building process practice. IPD is a project delivery approach that integrates people, systems, business structures and practices into a process that collaboratively harnesses the talents and insights of all participants to optimize project results, increase value to the owner, reduce waste, and maximize efficiency through all phases of design, fabrication, and construction (American Institute of Architects, 2007). Past IPD projects indicate that it has been applied in building construction, especially in the construction of healthcare facilities and hospitals (Cheng, Dale, Aspenson, \& Salmela, 2011).

\section{Past researches on $\mathrm{RC}$ approaches}

$\mathrm{RC}$ is a recent hot discussion subject in international journals. As part of investigation, a comprehensive search was conducted on Scopus indexing database for articles written between 2004 and 2013 having keywords "relational contract", "partnering", "alliance", "alliancing", and "integrated project delivery". The source journals considered were the top five international journals in the field of construction management, namely, Journal of Construction Engineering and Management, Construction Management and Economics, International Journal of Project Management, Journal of Management in Engineering, and Engineering Construction and Architectural Management.

It was noted that the total number of papers published in the five selected journals during the ten years interval was 144. The countries of origin of RC publication were analyzed along with the number of institute/university, researchers and papers involved. It was observed that the UK researchers were ranked top with papers of 40 , followed by United State (26), Australia (21), Sweden (14) and China (11). It is surprising to find China was ranked 6th with 11 publications, while to the best of our knowledge there are no formal RC approaches in China yet.

Among the overall publications, several research teams were identifiable because of their productive outputs, including the research teams led by Prof. Mohan Kumaraswamy at The University of Hong Kong, Prof. Albert Chan at The Hong Kong Polytechnic University, Prof. Per Erik Eriksson at Lulea Tekniska Universitet at Sweden, Prof. Florence Ling at National University of Singapore, and Prof. Peter Davis at The University of Newcastle. Their publications focus on the key elements and practices of RC approaches, such as mutual trust, joint risk management, relationship management, common goals, risk and opportunity sharing, and "no blame" culture. Their work underpins the effectiveness and efficiency of RC in the construction sector.

An investigation on the list of publications originated from China revealed that most of papers were the outputs of Chinese scholars cooperating with foreign institutes, mainly dealing with the implementations of $\mathrm{RC}$ in a foreign market. Only three of them investigated the possibility and empirical studies in the Chinese construction industry as follows: $\mathrm{Xu}$ et al. (2005) found that the 
most possible forms of collaboration and project delivery in Chinese construction markets for foreign contractors are design/build procurement route in conjunction with strategic alliances. Tang et al. (2006) collected data from the Chinese construction industry, which further revealed strong correlations among critical success factors of partnering, risk management, total quality management, use of incentives, and project performance. $\mathrm{Lu}$ and Yan (2007) investigated the underlying incentives for strategic partnering in China's construction industry. These three publications clearly demonstrate that the Chinese academia is well equipped with knowledge and research experience in the field of $\mathrm{RC}$, which is a desirable precondition of implementing RC in China's public construction projects.

\section{Feasibility of RC approaches in China's public projects}

\subsection{Theoretical analysis}

Relational contract theory (RCT) was originally developed by Macneil $(1974,1978,1983)$. The theory states that five relational norms exist in a RC, including "role integrity", "propriety of means", "preservation of the relation", "harmonization of relational conflict" and "supra contract norms".

Role integrity, the first relational norm in RCT, describes complex and long term behavior involving diverse obligations and more personal relations (Macneil, 1983). In the construction industry, commitment, particularly on a long term basis, is an important aspect of performing role integrity in a RC contractual arrangement (Rahman \& Kumaraswamy, 2004). A long-term commitment may indicate the contracting parties' willingness to enter potential collaborative opportunities in the current and future projects.

Propriety of means, the second relational norm in RCT, refers to "the way relations are carried on as distinct from more substantive matters, including not merely formal and informal procedures, but such things as customary behavior, often of the most subtle kind" (Macneil, 2000). In construction projects, it is interpreted as building a winwin scenario through a range of contractual arrangements, such as equitable risk allocation (Rahman \& Kumaraswamy, 2008), gain/pain share arrangement (Yeung, Chan, A. P. C., \& Chan, D. W. M., 2012), and clarity of contract conditions (Ling, Ong, Ke, Wang, \& Zou, 2014).

Preservation of the relation, the third relational norm in $\mathrm{RCT}$, is primarily an intensification and expansion of the norms of contractual solidarity and flexibility (Blois, 2002; Macneil, 1983). Contractual solidarity involves preservation of particular memberships in relations, indicating that contracting parties should select cooperative behaviors to facilitate the stability of the relations (Macneil, 1983). In the area of construction, it can be operationalized as a common goal (Rahman \& Kumaraswamy, 2004), and joint coordination and monitoring plans (including joint risk management) or so-called collective/combined responsibilities (Ling, Ke, Kumaraswamy, \& Wang, 2014). Flexibility means the adequate attention and the adaptability to the demand of changes. In the construction sector, the meaning is still identical as the willingness and adaptability to changes or unclear issues (Rahman \& Kumaraswamy, 2004; Rahman \& Kumaraswamy, 2008).

Harmonization of relational conflict, the fourth relational norm in RCT, is mainly a combination of the norms of flexibility and harmonization of the social matrix (Macneil, 1983). Flexibility is essential to meet countless kinds of changes, thereby achieving the harmonization of relations. Its meaning in the construction projects has been discussed above. An aspect of harmonization of the social matrix in the construction sector is an agreed conflict resolution mechanism (Walker, Hampson, \& Peters, 2002). It also calls for attention on the relationships, including previous relationships, ongoing relationships and future relationships among contracting parties (Ling \& Ke et al., 2014).

Supra contract norms, the fifth relational norm in RCT, do not imply that these are beyond the bounds of contractual relations, but because they are not particularly contractual (Macneil, 1983) and are in fact the broad norms of behaviors in a particular context (Blois, 2002). As preservation of the relation and harmonization of relational conflict require adherence to the supra contract norms (Macneil, 1983), they include the following norms in the construction context: mutual trust (Walker et al., 2002), open communication (Rahman \& Kumaraswamy, 2004) and teamwork (Love, Mistry, \& Davis, 2010).

Generally speaking, the above analysis indicates the possible mapping from theory to practices, and establishes a link between RC approaches and the guiding RCT. Past researches have also proved that RCT is applicable to the construction sector through RC approaches (Ling \& Ke et al., 2014).

\subsection{Cultural analysis}

The core values of Chinese culture like maintaining harmony, building trust among people and collective benefits (Zuo, Chan, Zhao, Zillante, \& Xia, 2013) are arguably in line with the principles of RC. The Chinese cultural values provide possibilities for the implementation of RC approaches because they emphasize mutuality and respect, trust and friendship all which are basically the factors that make RC implementation successful (Kwan \& Ofori, 2001).

The most popular policy in China related to $\mathrm{RC}$ is the "building of a harmonious socialist society by 2020 ", which was adopted at the conclusion of the Sixth Plenary Session of the 16th Central Committee of the Communist Party of China on October 11, 2006. The policy points out that social harmony is the intrinsic nature of socialism with 
Chinese characteristics. It reinforces the emphasis on harmony in context of the cultural diversity in modern China. This emphasis is not only seen in modern China, but also existed in ancient times, with the most famous saying "in the application of the rites, harmony is to be prized" by the philosopher Confucius. Besides the emphasis on harmony, mutual trust is very important as well. Confucius also said that a man who is not trustworthy could not accomplish much.

In the construction sector, the Chinese culture of valuing relationships (so called "guan xi" in Chinese) has been practiced all the time. Many construction organizations consider a good relationship with clients as a critical success factor. The authors do not suggest that the values of culture instead of contractual arrangements can guarantee the ethical behaviours of contracting parties, rather the similarity between the Chinese culture and the principles of $\mathrm{RC}$ can bring in the high acceptance of $\mathrm{RC}$ philosophes for contracting parties.

\subsection{Practical analysis}

The absence of formal RC approach in China does imply that $\mathrm{RC}$ principles or behaviors were not practiced in past construction projects. In a previous studies (Ling \& Ong et al., 2014), a survey was conducted in Beijing to evaluate the performance outcomes of completed public construction projects and the extent to which $\mathrm{RC}$ practices were present, observed, practiced or emphasized in those projects. It was found that thirty two RC practices were significantly correlated with the performance outcomes of public construction projects in Beijing and that eight of those key practices were not adopted to a significant extent but were considered significantly correlated with performance outcomes. The results indicated that RC practices were adopted to varying extents in public projects. The findings contribute to knowledge by identifying the specific RC practices that could boost project performance significantly. Another contribution to knowledge is the discovery that the RCT is applicable to public projects notwithstanding the need to keep relations at arm's length. That study also found many significant factors that drive the adoption of RC in Beijing. The results contribute to knowledge by showing that it is feasible to adopt $\mathrm{RC}$ practices in public construction projects in an open market economy, even though these projects are usually subject to a plethora of rules, regulations and institutional constraints. It was found that Beijing experiences 6 significant barriers adopting $\mathrm{RC}$ practices. This research further contributes to knowledge by showing that these barriers are consistent with the government adopting a tight control and playing a big part in directing and controlling construction enterprises, causing public officials to lack initiative and empowerment, and preferring the status quo.

In summary, from practical perspective it can be seen that $\mathrm{RC}$ principles or behaviors are found to some extent in the traditional public construction projects in China. This reinforces the possibility of implementation of formal RC approach in China's public projects.

\section{Key points of RC approach implementation}

It is recommended that the Chinese government makes use of its influence and controlling authority to encourage wider adoption of $\mathrm{RC}$ especially in public projects by introducing public policies and providing more opportunities for firms to work collaboratively (Ling \& Ong et al., 2014). It is important that the government efficiently and professionally choose the best appropriate procurement strategy for public projects. It is further recommended that Chinese public clients appoint highly competent representatives to manage their projects so that they can be empowered to make right decisions. In general, RC approaches are more applicable to projects that have great project value, sufficient internal resources, high risks, and urgent project start. Ongoing public clients, who have the construction project experience and will have future projects to be constructed, may have less difficulty to offer future relationships with private contractors. RC approaches may hence be possible with a long-term relationship founded on regular spending process (Tookey, Murray, Hardcastle, \& Langford, 2001).

Before wider adoption of RC approaches, pilot projects could be selected. Its purpose can be to test whether the implementation of RC approaches in China's public projects will achieve the project performance in theory, and whether its implementation will have conflicts with current regulatory framework. The selection of a pilot project can be a short-term and medium investment public project, so that it may not cause a huge waste of money in case RC approach is not applicable. For instance, given the positive experiences reported on the use of New Engineering Contract (NEC, one of the particular RC approaches) form in the UK and other regions, the Hong Kong Development Bureau decided to use the NEC form for several public works in Hong Kong. One such project was the improvement project works in Sai Kung. The NEC was adopted with a view of gaining experience and assessing the suitability of NECs for future public works projects (Ling, Ning, Ke, \& Kumaraswamy, 2013).

Another lesson that can be obtained from the Hong Kong experience is the frequent training workshops and lectures arranged by professional building associations, government departments and universities. For examples, the Civil Engineering and Development Department regularly has a series of training workshops in which contractors about to start a $\mathrm{RC}$ projects are required to attend, and others are encouraged to attend. The universities such as the Hong Kong Polytechnic University offer training courses for NEC that aims at providing an 
introduction to the NEC and examining the various clauses and options available under the contract. These courses are approved by several Hong Kong institutes and are identified as their continuous professional development courses. All those above mentioned training activities are proved to be effective and efficient means for promoting the application of RC approaches in Hong Kong.

Finally, while it is important to spend time to form and nurture relationships, Chinese contracting parties should not over do it because relationships have limitations (Ling \& Ong et al., 2014). For example, it cannot be transferred from organization to organization, but reside within individuals.

\section{Conclusions}

The major purpose of this study was to investigate the feasibility of implementation of $\mathrm{RC}$ approaches in the China's public construction projects. The international implementations of $\mathrm{RC}$ approaches were reviewed, in which successful experiences were noted. Past researches on RC approaches showed that the Chinese academia is equipped with the knowledge and research experience required in the field of $\mathrm{RC}$, this reinforces the possibility of implementing RC in China's public construction projects. A further detailed discussion in terms of theoretical analysis, cultural analysis and practical analysis also proved the feasibility of implementation of formal RC approaches in the publica projects. Lastly, the major key points for successful implementation of the $\mathrm{RC}$ approaches in China were discussed.

\section{References}

American Institute of Architects. (2007). Integrated Project Delivery: A Guide. Washington D C: American Institute of Architects

Association of Consultant Architects. (2008). PPC2000: ACA Standard Form of Contract for Project Partnering. UK: Association of Consultant Architects

Blois, K. (2002). Business to business exchanges: a rich descriptive apparatus derived from Macneil's and Menger's analyses. Journal of Management Studies, 39, 523-551

Cheng, R., Dale, K., Aspenson, A., \& Salmela, K. (2011). IPD Case Studies. Minnesota: AIA Minnesota and School of Architecture University

Construction Industry Institute. (1991). In Search of Partnering Excellence. USA: Construction Industry Institute

Cox, A., \& Ireland, P. (2002). Managing construction supply chains: the common sense approach. Engineering Construction and Architectural Management, 9, 409-418

Davis, P. R., \& Love, P. E. D. (2011). Alliance contracting: adding value through relationship development. Engineering Construction and Architectural Management, 18, 444-461
Department of Infrastructure and Transport. (2011). National Alliance Contracting Guidelines: Guide to Alliance Contracting. Australia: Department of Infrastructure and Transport

Kwan, A. Y., \& Ofori, G. (2001). Chinese culture and successful implementation of partnering in Singapore's construction industry. Construction Management and Economics, 19, 619-632

Lahdenperä, P. (2012). Making sense of the multi-party contractual arrangements of project partnering, project alliancing and integrated project delivery. Construction Management and Economics, 30, 5779

Ling, F. Y. Y., Ke, Y., Kumaraswamy, M. M., \& Wang, S. (2014). Key relational contracting practices affecting performance of public construction projects in China. Journal of Construction Engineering and Management, 140, 04013034

Ling, F. Y. Y., Ning, Y., Ke, Y., \& Kumaraswamy, M. M. (2013). Modeling relational transaction and relationship quality among team members in public projects in Hong Kong. Automation in Construction, 36, 16-24

Ling, F. Y. Y., Ong, S. Y., Ke, Y., Wang, S., \& Zou, P. X. W. (2014). Drivers and barriers to adopting relational contracting practices in public projects: comparative study of Beijing and Sydney. International Journal of Project Management, 32, 275-285

Love, P. E. D., Mistry, D., \& Davis, P. R. (2010). Price competitive alliance projects: identification of success factors for public clients. Journal of Construction Engineering and Management, 136, 947956

Lu, S., \& Yan, H. (2007). An empirical study on incentives of strategic partnering in China: views from construction companies. International Journal of Project Management, 25, 241-249

Macneil, I. R. (1974). The many futures of contracts. Southern California Law Review, 47, 691-816

Macneil, I. R. (1978). Contracts: adjustment of long-term economic relations under classical, neoclassical, and relational contract law. Northwest University Law Review, 72, 854-906

Macneil, I. R. (1983). Values in contract: internal and external. Northwest University Law Review, 78, 340-347

Macneil, I. R. (2000). Contracting worlds and essential contract theory. Social \& Legal Studies, 9, 431-438

Rahman, M. M., \& Kumaraswamy, M. M. (2002). Joint risk management through transactionally efficient relational contracting. Construction Management and Economics, 20, 45-54

Rahman, M. M., \& Kumaraswamy, M. M. (2004). Contracting relationship trends and transitions. Journal of Management in Engineering, $20,147-161$

Rahman, M. M., \& Kumaraswamy, M. M. (2008). Relational contracting and teambuilding: assessing potential contractual and noncontractual incentives. Journal of Management in Engineering, 24, 48-63

Tang, W., Duffield, C. F., \& Young, D. M. (2006). Partnering mechanism in construction: an empirical study on the Chinese construction industry. Journal of Construction Engineering and Management, $132,217-229$

Tookey, J. E., Murray, M., Hardcastle, C., \& Langford, D. (2001). Construction procurement routes: redefining the contours of construction procurement. Engineering Construction and Architectural Management, 8, 20-30 
Walker, D. H. (1998). The contribution of the client representative to the creation and maintenance of good project inter-team relationships. Engineering Construction and Architectural Management, 5, 51-57 Walker, D. H. T., Hampson, K., \& Peters, R. (2002). Project alliancing vs. project partnering: a case study of the Australian National Museum Project. Supply Chain Management: An International Journal, 7, 83-91

Xu, T., Smith, N. J., \& Bower, D. A. (2005). Forms of collaboration and project delivery in Chinese construction markets: probable emer- gence of strategic alliances and design/build. Journal of Management in Engineering, 21, 100-109

Yeung, J. F. Y., Chan, A. P. C., \& Chan, D.W.M. (2012). Defining relational contracting from the Wittgenstein family-resemblance philosophy. International Journal of Project Management, 30, 225239

Zuo, J., Chan, A. P. C., Zhao, Z., Zillante, G., \& Xia, B. (2013). Supporting and impeding factors for partnering in construction: a China study. Facilities, 31, 468-488 